\section{VB-7 579}

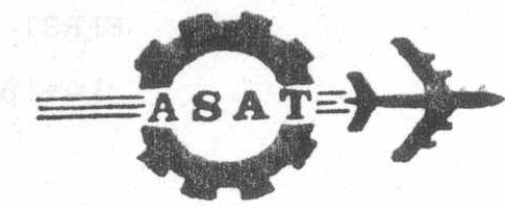

MILITARY TECHNICAL COLLEGE

CAIRO - EGYPT

$r$

VIBRATION SIGNATURE ANALYSIS OF TURBOJET ENGINES

*Maj. Gen. Dr. A. MAHER, +Col. Dr. S. KOSSA,

${ }^{+}$Col. Dr. M. KADDAH, **Col. M. El-HUSSEINY

ABSTRACT

Turbojet engines exhibit vibrations, whose amplitudes change with the life time and the operating conditions of the engine. The analysis of vibration signals in the frequency domain provides quantitative information about the dynamic behaviour of the engine and a qualitative measure of its performance. The diagnosis of engine malfunctions and the optimzation of maintenance costs are few examples for which the signal analysis consideration becomes exceptionally important. The present paper outlines the proper applications of a vibration measuring system to a number of turbojet engines. Types of transducers, mounting location, signal conditioning and signal recording and analysis used in this development are discussed. The paper includes a number of frequency spectra, obtained using Fast Fourier Transform (FFT) analysis for a single - shaft and a double - spool turbojet engines.

*Chair of Mechanics and Elasticity, Military Technical College, Cairo, EGYPT. +Aeronautical Department, Military Technical College, Cairo EGYPT.

** Engineer, Egyptian Airforce. 
In recent years, vibration and noise analysis has been used increasingly for the detection and early diagnosis of potential failures of rotating machinery [1]. Noise and vibration signals measured at the external surfaces of a rotating machine contain valuable information regarding the internal processes within the machine, and can provide convenient means of judging the machine's running condition. Traditional methods of machinery protecting systems have used a single "RMS" or peak level value of vibration amplitudes as limiting criteria. More recent techniques, which are used for "On - condition maintenance" and malfunction diagnosis, have utilized systems which can perform frequency analysis. Some examples of the application of spectrum analysis to various types of rotating machines are given in references $[2-4]$.

The main advantages of using vibration measurement and analysis for machinery maintenance and protection are:

a) Increasing reliability and productivity by elimination of unexpected breakdowns.

b) Reducing maintenance costs by increasing the average time between ", overhauls

c) Reducing repair duration as the necessary action is planned in advance.

d) Elimination of secondary damage

e) Replacement parts can be procured with less urgency and the spare-part stock can be reduced

Over the past few years the instrumentation required to accomplish the vibration signature analysis in a practical manner has become available in the form of piezoelectric accelerometer, swept filters, real time analyzers and other vibration measuring equipment [5]. However, still much work is required for the analysis of extremely complex vibration signatures of turbojet engines, particularly for double-spool turbojet engines. Some of the reasons contributing to the complexity of the problem are : 1- The causes of vibration in turbojet engines are enormous such as unbalance, shaft thermal bowing, misalignment, loosness or movement of engine parts, contact between stationary and rotating parts, aerodynamic 
forces, defected gears, bearings and etc. [6].

2- Signals obtained from turbojet engines often contain pseudo random noise. Also the frequency components do not remain stationary, for example, a compressor having 72 blades rotating at $12000 \mathrm{rpm}$ would experience a frequency fluctuation of $288 \mathrm{~Hz}$ in the blade passing frequency for a speea variation of $\pm 1 \%$.

3- Data acquisition, reduction and interpertation of a massive amount of information.

4- The casing temperatures are considerably high near the turbine which may effect the transducer performance.

5- The cross excitation which frequently occurs in the case of multispool turbojet engine.

The objective of this paper is to outline the application of a vibration signature analysis technique to turbojet engines. Attention has been given to the description and utilization of the employed vibration measuring system.

It is worth noting that the emphasis is put in this paper on the illustration of the applicability of the used measuring system for turbojet engine signature. Some examples of the measured shaft and a double-spool turbojet engines are included. Details of the analysis technique and its application in malfunction diagnosis will be published laterly.

\section{VIBRATION MEASURING SYSTEM}

Fig. 1 is a schematic representation of the instrumentation set-up for measuring and analysis of the vibration signatures of the tested turbojet engines. Some details of the tests are given in APPENDIX.

\section{Accelerometers}

The most suitable transducer for jet engine applications is the piezoelectric accelerometer which has the following advantages [7]:

* wide useful frequency range

* suitable for high temperature applications

* long life (there is no moving parts as in velocity transducers) 


\begin{tabular}{|l|l|}
\hline VB-7 & 582 \\
\hline
\end{tabular}

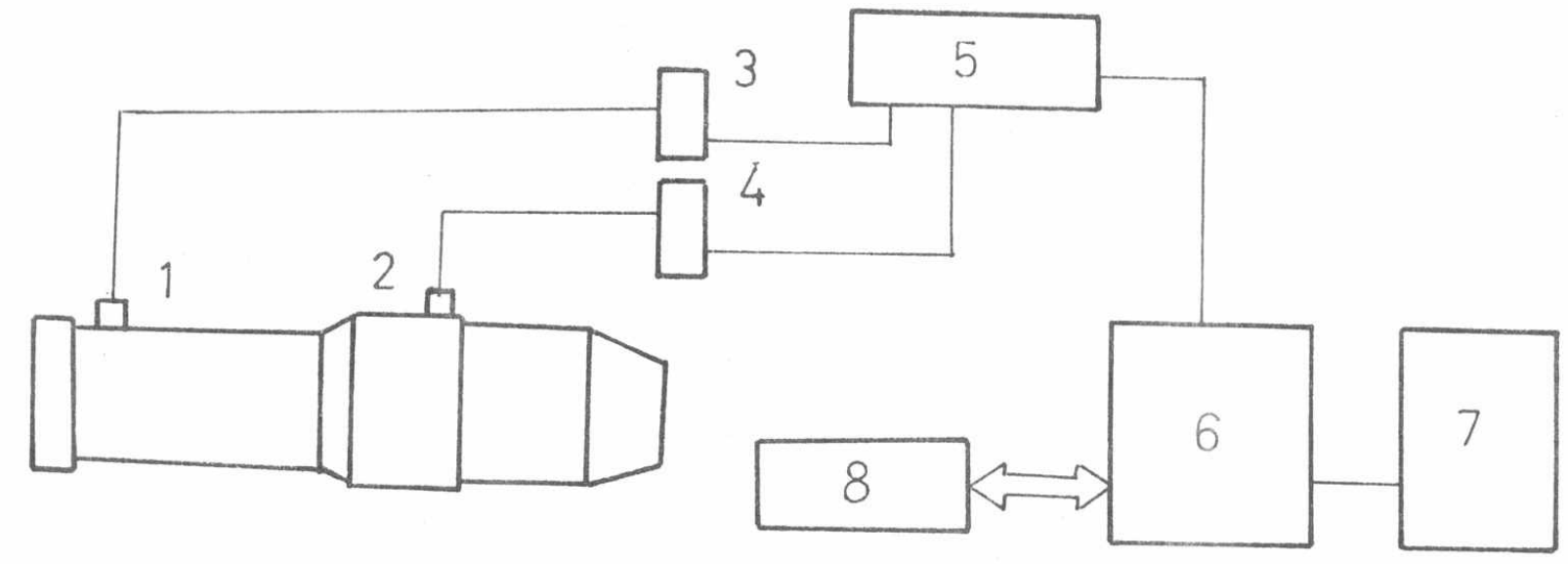

$$
\begin{aligned}
& \text { 1,2 Accelerometers } \\
& \text { 5- Tape recorder } \\
& \text { 7- x-y Plotter }
\end{aligned}
$$

$$
\begin{aligned}
& 3,4 \text { Charge amplifiers } \\
& 6 \text { Narrow band FFT analyzer } \\
& 8 \text { Micro computer. }
\end{aligned}
$$

Fig.1. Scheme of the instrumentation set-up

Two piezoelectric accelerometers are used having a maximum working temperature of $400^{\circ} \mathrm{C}$, charge sensitivity $1,04 \mathrm{pc} / \mathrm{ms}^{-2}$ and resonant frequency of about $30 \mathrm{kHz}$.

Mounting Brackets and Accelerometers Locations.

The used brackets are small rigid steel parts of very high resonant frequency. Each bracket is attached to a bearing housing support member on the engine outer casing. The accelerometer is attached by three Allen screws to the bracket. One accelerometer is located near the compressor front bearing and the other near the turbine bearing. A stream of cooling air is supplied for reducing the temperature of the accelerometer situated near the turbine.

Charge Amplifier.

Two charge amplifiers are used of the following leatures:

* built in integrators to convert the acceleration proportional output from accelerometer either to velocity or to displacement signals.

* range of high-pass and low-pass filters

$L^{*}$ calibrated variable gain tacility combined with a secondary gain 
adjustment tc normalize the transducer sensitivity so that the output sensitivity is a convenient round figure. This feature facilitates the calibration considerably.

The output signal from the charge amplifier may either be recorded on magnetic tape for analysis in the laboratory or fed directly into the analyzer. Magnetic Tape Recorder The used recorder is a 4 chanel analog instrumentation tape recorder which has a high signal to noise ratio (to permit examining low level signals). The recorder has provisions for both FM (Frequency Modulated) and Direct (Amplitude Modulated) recording and reproduction with an upper frequency range of about $60 \mathrm{kHz}$.

Narrow - band Frequency Analvzer:

The used FFT (Fast Fourier Transform) analyzer: has the following features:

* A broad dynamic range of $80 \mathrm{~dB}$ which is essential when analyzing rotating machine vibration to get more reliable detection and prediction of the machine conditions [8].

* Wide frequency range up to $20 \mathrm{kHz}$.

* Linear, exponential or store max. averaging over 1- 2048 spectra. This feature is invaluable for reducing and stabilizing the random content of the jet engine complex vibration signature.

* Protected memory for tne storage uf a aisplayed spectra with the possibility of slow or fast alternate of input and stored spectra for the dirert comparison.

* Wide angle zoori to increase frequency resolution for example to resolve the side bands around the toothmesh frequency component.

A hard copy of the spectrum is obtained from an $x-y$ plotter connected to the analyzer. The output signal from the analyzer is also fed to a microcomputer for further processing. 
Micro computer:

The micro computer is incorporated into the measuring system to perform the following tasks:

* Creation and stnrage of a reference spectrum which should account for possible engine speed changes for comparing with subsequent spectra.

* Comparison of a measured spectrum with the reference spectrum and indicating the frequencies where changes in the vibration level exceeding the prescribed tolerances have occured.

A detailed discussion of the role of the micro computer in the analysis and fault detection together with some examples of the obtained results will be the subject of a later paper.

EXAMPLES OF THE MEASURED VIBRATION SPECTRA OF TURBOJET ENGINES

Fig. 2. depicts a high frequency spectra of a single-shaft turbojet engine. As it may be expected, almost all the spectralpeaks are directly related to the engine running speed. (In the presented frequency spectra, the freqency corresponding to the engine running speed, i.e. the First Engine order is denoted by $\mathrm{E}$ ). As the accelerometer was placed onto the front casing of the compressor in this measurement, the blade passing frequencies of the compressor stages are clearly distinguished in the frequency spectrum. For example, there is an obvious 29 engine order (29E) which represents the blade passing frequency of the first stage of the compressor, this observation is vindicated as there are 29 blades on the first row of the compressor rotor. The spectrum also shows significant frequency components at $58 \mathrm{E}$ and $87 \mathrm{E}$ which relate to the first and second harmonics of the blade passing frequency of the first stage of compressor. Blade passing frequency is due to the impinging of the ortor blade wakes onto the stator vanes producing a periodic disturbance equal to the product of the rotor speed and the number of rotor blades.

It is interesting to note that even the blade passing frequency of the last compressor stage (the ninth stage) is easily detected at 65E. This observation may be explained by assuming that spinning pressure patterns generated by downstream rotor when impinging onto the stator vanes does not only continue spiralling down stream away from the stator, but can also spiral back upstream. Hence a rotor stage can excite an upstream stator vane in 
addition to the downstream stator vanes-as the experimental results show. A low frequency spectrum of a double-spool turbojet engine is shown in Fig. 3. The low pressure rotor shaft is rotating by $3750 \mathrm{r} \cdot \mathrm{p} . \mathrm{m}\left(f_{L}=62,5 \mathrm{~Hz}\right) \mathrm{wh}-$ ile the high pressure rotor shaft is rotating by $5930 \mathrm{rpm}\left(\mathrm{f}_{\mathrm{H}}=98,8 \mathrm{~Hz}\right)$. Fig. 3. depicts the two fundamental frequencies $f_{L}$ and $f_{H}$ in addition to a series of sum and difference frequencies.

The generation of sum and difference frequencies from a truncated beat waveform in rotating machines had been discussed in reference [9].

Fig. 4. illustrates the high frequency spectrum of a double spool turbojet engine. As the two shafts are rotating by almost the same speed. In this case $\left(f_{L}=185,8 \mathrm{~Hz}\right.$ and $\left.f_{H}=188,6 \mathrm{~Hz}\right)$, neither sum nor difference frequencies appear in the spectrum. Again, the spectral peaks are easily detected and related to the engine order. For example, the significant spectral peaks at $24 \mathrm{E}$ and $53 \mathrm{E}$ correspond to the blade passing frequencies of the first and second stages of the compressor. The spectral peak at $48 \mathrm{E}$ can be identified either as the first harmonic of the blade passing frequency of the first rotor stage $(2 \times 24 \mathrm{E})$ or as the gear meshing frequency of the driving gear mounted on the low pressure rotor shaft.

Although high frequency spectra are expected to contain vital information about the characteristics of rolling ellement bearing failure, gear meshing and tooth loading abnormalities and dynamic response of rotating and stationary components such as turbine and compressor blades. In order to obtain a truly representative picture of the turbojet engine's mechanical condit= ions, it is necessary to examine also the low frequency spectram. Most common causes of vibration such as unbalance, bent shaft, mechanical looseness and misalignment occur at the low engine order components of $1 \mathrm{E}$ and $2 \mathrm{E}$. Since the low order components are not detectable from the high frequency spectrum of Fig. 4. a lower frequency range is needed and depicted in Fig. 5. It is worth noting that the spectral peak at $1,5 \mathrm{E}$ was found to be fixed at the frequency of $265 \mathrm{~Hz}$ during the engine speed variation. Occurance of such phenomina is due to the resonance of some engine component. However further inspection of the einge is required to ascertain which component is responsible for this fixed frequency peak.

Photographs of the measuring system are shown in Fig.6 and 7 . 
CONCLUSIONS

1- A system is developed for measurement and analysis of turbojet enginè vibration signature which provides a highly defined detailed record of the engine vibration characteristics.

2- The developed system can form the basis of a meaningful predictive and preventive maintenance programme for turbojet engines and for rotary machines in general

\section{REFERENCES}

1. Bosmans, R.F. "Detection and Early Diagnosis of potential Failures of Rotating Machinery" Noise and Vibration Control Worldwide, Vol. 15, pp. 125-132, 1984 .

2. Downham, E. and Woods, R. "The Rationale of Monitoring Vibration on Rotating Machinery in Continuously Operating Process Plant" ASME paper No. 71-Vibr- 96, 1971.

3. Borhaug, J.E. and Hanna A.T. "Vibration Signature Analysis - Application to Onstream Diagnosis of paper Mill Machinery" Western International Meeting of Pulp and Paper Industry, Vancouver, Canada, 1973.

4. Soundranayagam S. and Others "Vibration signature Analysis of Rotating Systems" Proceedings of the Second Cairo University MDP Conference, pp. 73-80, 1982 .

5. Broch, J.T. "Mechanical Vibration and Shock Measurements" Bruel and Kjaer Publication, Denmark, 1980.

6. Sohre, J.S. "Operating Problems With High speed Turbomachinery Causes and Correction" ASME Petrolum Mech. Eng. Conf., Dallas, 1968.

7. Kidd, H.A. "Development of a Case Vibration Measurement system for the DC-990 Gas Turbine" ASME Paper No. 84-GT-143, 1984.

8. Maersk - Moller, H. "Vibration Measurement for maintenance" Pulp \& Paper Canada, Vol. 83, No. 1, 1982.

9. Eshleman R.L. "The Role of Sum and Difference Frequencies in Rotating Machinery Fault Diagnosis" C272/80, I. Mech. Eng., Conference of Vibration in Rotating Machinery, pp. 145-149, 1980. 
APPENDIX

Tests were carried out on two engines with the following pecularities :

Iest NO.l (Fig. 2)

A single-Spool Turbojet Engine

Compressor: Nine stages axial flow compressor.

Number of rotor blades of the compressor stages are 29,17, $28,33,32,53,65$ and 65 , respectively.

Turbine: Two stages axial gas turbine.

Number of rotor blades of the turbine stages are 76 arid 64, respectively.

Tests No.2. ,3,4 (Fig.3,4,5)

A Double-Spool Turbojet Engine.

Compressor: Three stages L.P.C. and five stages H.P.C.

Number of rotor blades of the compressor stages are 24,53 , $53,57,65,66,78$ and 74 , respectively.

Turbine: Two stages axial gas turbine.

Number of blades of the HPT rotor blades is 61 and for LPT is 64.

Fig.6. illustrates the mounting of the accelerometer on the turbojet engine. Testing equipments are shown in Fig.7. 

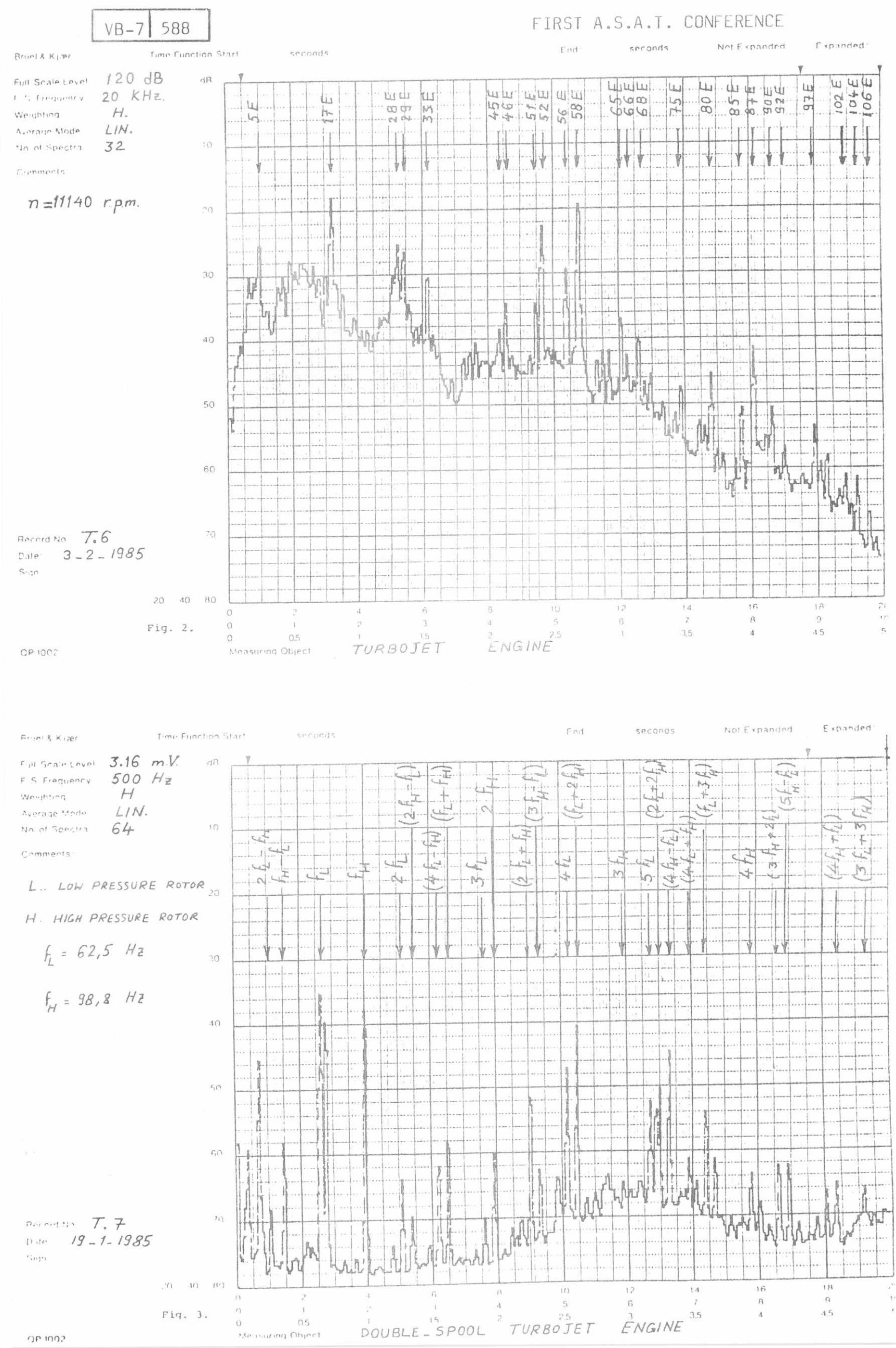

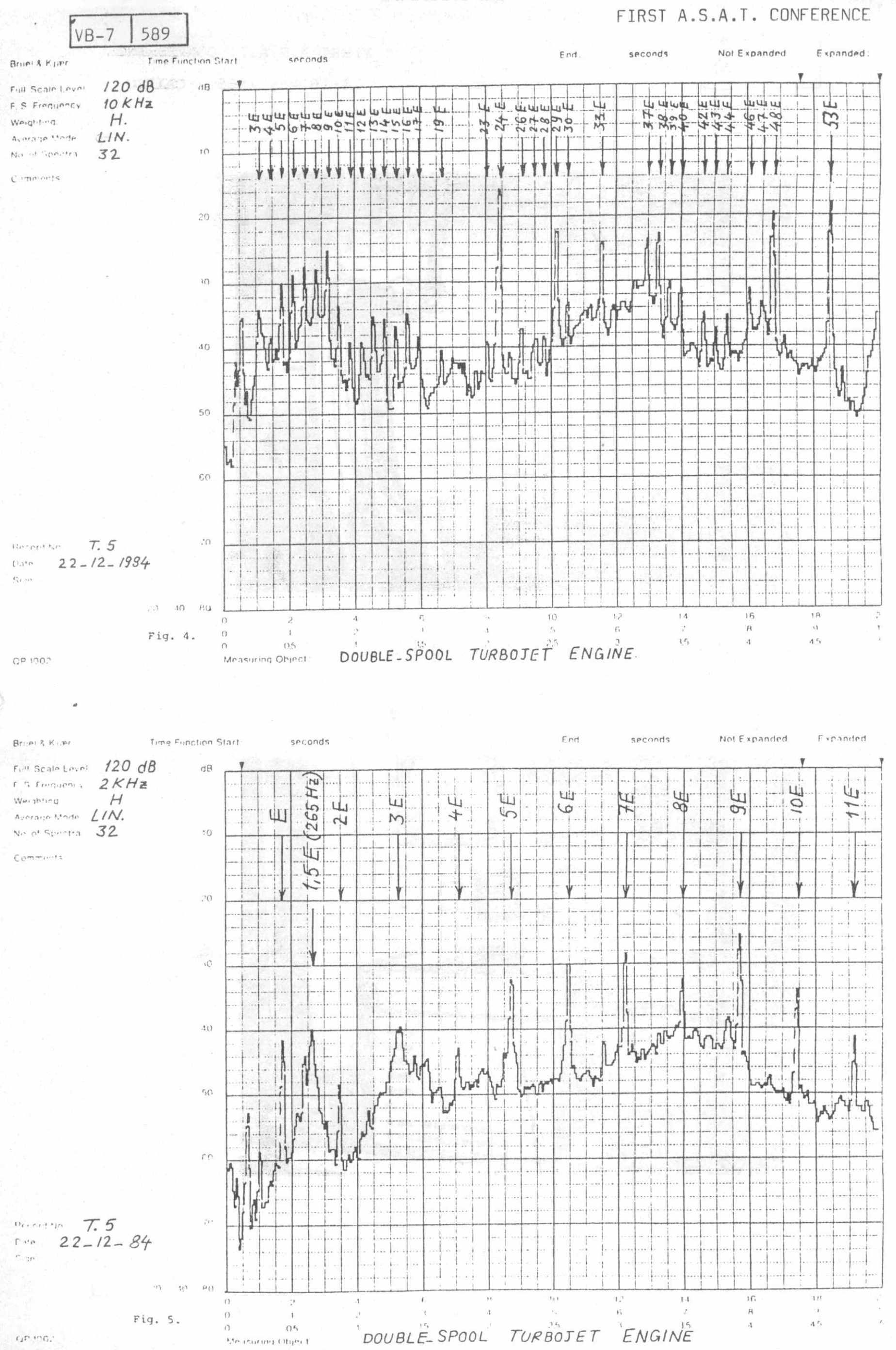


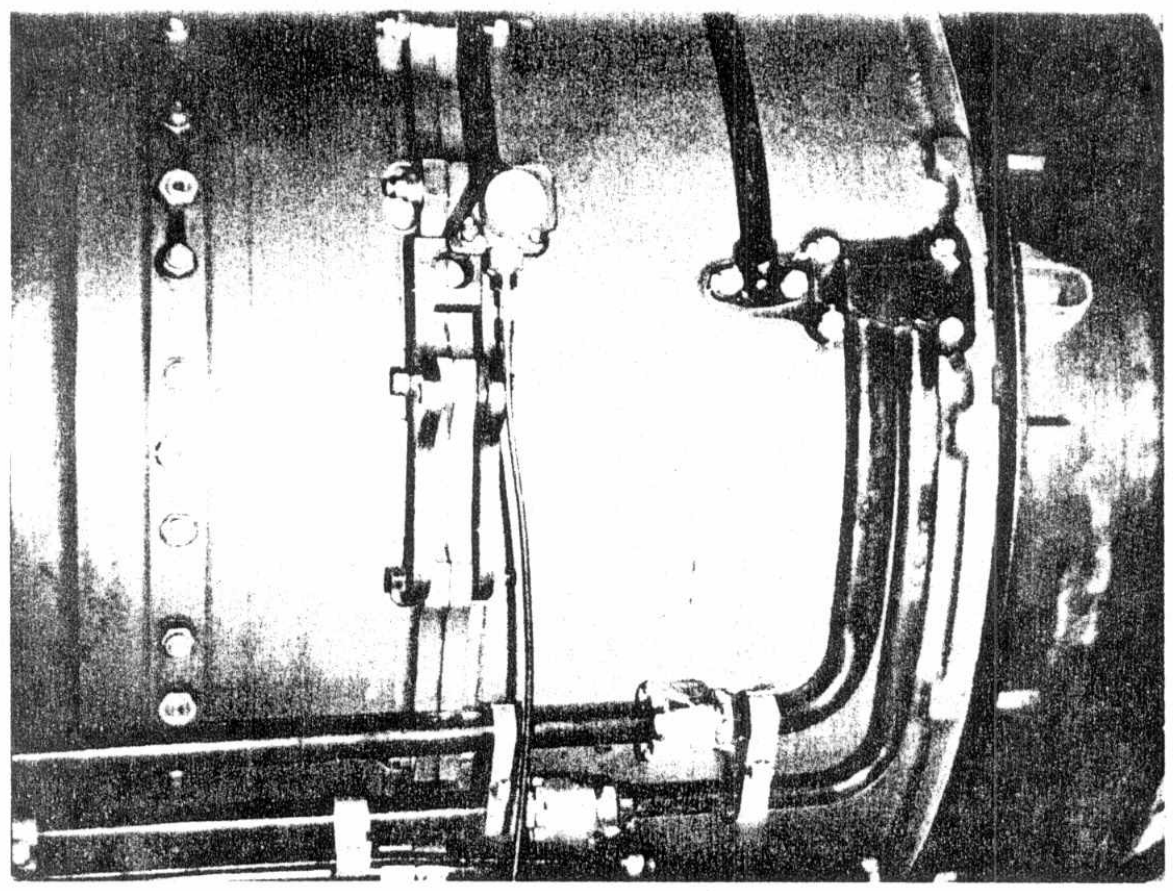

Fig.6. Tested Jet Engine With the Accelerometer.

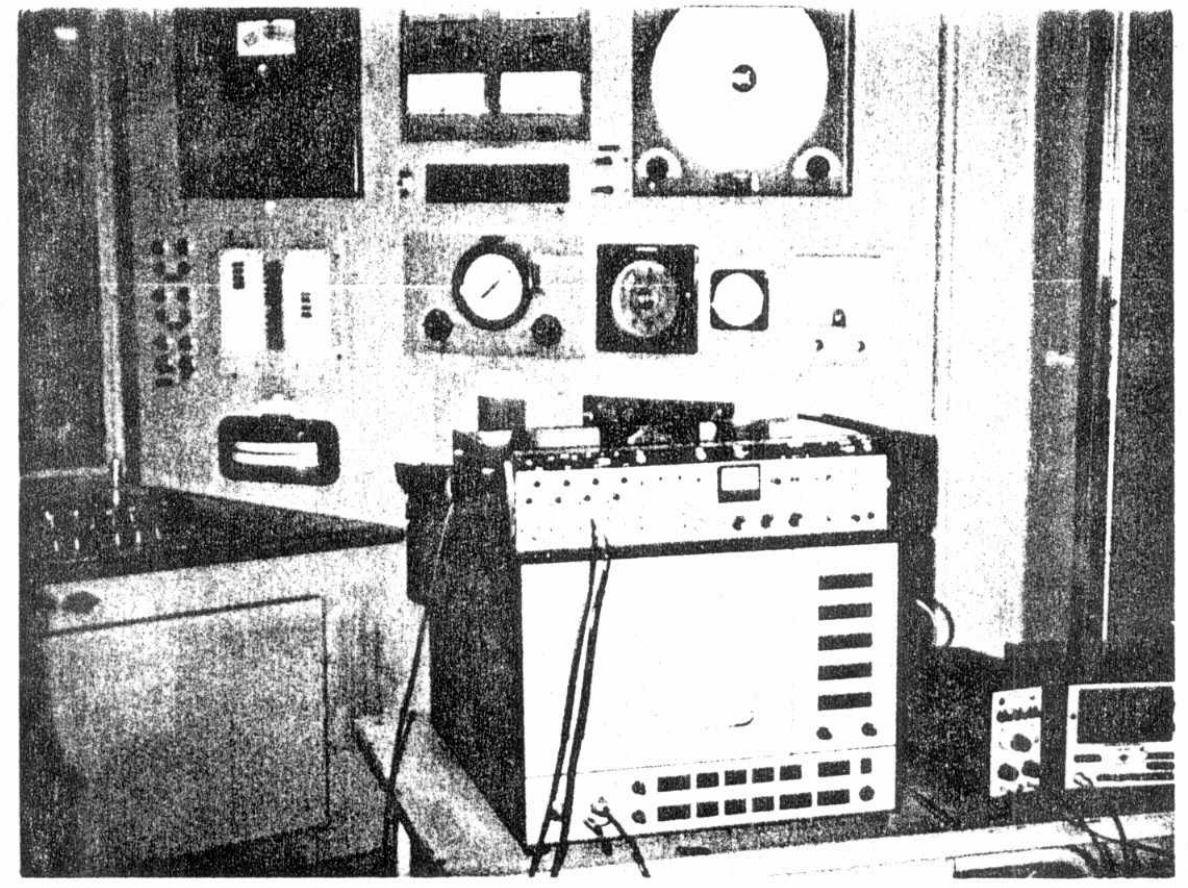

Fig.7. Vibration Measuring Equipment. 